\title{
Tamanho de amostras para aval iação da severidade da queima das folhas do inhame
}

\author{
Sami J orge M ichereff ${ }^{1}$, M arissônia de A raújo N oronha ${ }^{1}$, L uiz A ntonio M affia ${ }^{2}$
}

${ }^{1}$ D epartamento de A gronomia - Á rea de Fitossanidade, U niversidade Federal Rural de Pernambuco, CEP 52171-900, Recife, PE ; 2 U niversidade Federal de Viçosa, Viçosa, M G.

A utor para correspondência: Sami J. M ichereff. sami@ depa.ufrpe.br

Data de chegada: 18/04/2006. A ceito para publicação em: 23/03/2007

1351

\section{RESUMO}

M ichereff, S.J .; N oronha, M .A .; M affia, L .A. Tamanho de amostras para avaliação da severidade da queima das folhas do inhame no campo. Summa Phytopathologica, v.34, n.2, p.189-191, 2008

A queima das folhas, causada por Curvularia eragrostidis, é a principal doença foliar do inhame no Nordeste brasileiro. Para subsidiar a quantificação da doença no campo, foram determinados os tamanhos ideais das amostras em 15 plantios comerciais de inhame (cv. Da Costa) localizados na Zona da Mata de Pernambuco. Em cada plantio foram amostradas 100 plantas e a severidade da doença avaliada em extratos de 5, 15 e 30 fol has por planta. Os dados obtidos em cada área foram analisados pelo método que especifica o erro aceitável, determinado pelo coeficiente de variação da média. A severidade da doença variou entre 0,41 a $22,34 \%$ e foi correlacionada negativamente $(\mathrm{P}=0,05)$ com o tamanho da amostra. Na média dos plantios, 0 aumento da amostra de 15 para 30 folhas por planta propiciou pequena redução no número de plantas a ser avaliado, diferindo do observado quando 0 aumento foi de 5 para 15 folhas. Considerando os resultados obtidos e um erro aceitável de $10 \%$, em futuros levantamentos da severidade da queima das folhas em plantios de inhame do Nordeste brasileiro recomenda-se a utilização de uma amostra de 37 plantas/ha e 15 folhas/planta.

Palavras-chave adicionais: D ioscorea cayennensis, Curvularia eragrostidis, amostragem, quantificação de doença, epidemiologia.

\section{ABSTRACT}

M ichereff, S.J.; Noronha, M.A.; M affia, L.A. Sample size for assessment of yam leaf blight severity. Summa Phytopathologica, v.34, n.2, p.189-191, 2008

Leaf blight, caused by Curvularia eragrostidis, is the major foliar disease of yam in the Brazilian Northeast. Optimum sample size were determined in 15 commercial yam (cv. Da Costa) areas, located at Zona da Mata, Pernambuco State, N ortheast of Brazil, aiming to orientate the disease assessment of yam leaf blight in field conditions. Disease severity was assessed in 100 plants by field in extracts of 5 , 15 , and 30 leaves by plant. The data set from each area were analyzed by a method that specified the level of acceptable error, determined by the mean coefficient of variation. The disease severity ranged between 0.41 and $22.34 \%$ and was negatively correlated $(P=0.05)$ with the sample size. The increase of 15 to 30 leaves sampled for plant result small reduction in the total number of plants to be sampled differing of the observed when the increase was from 5 to 15 leaves. Based on data set and considering $10 \%$ of acceptable error, future surveys of yam leaf blight severity in Northeast fields should analyze 37 plants/ha and 15 leaves/plant.

Additional keywords: Dioscorea cayennensis, Curvularia eragrostidis, sampling, disease assessment, epidemiology.

A queima das folhas, causada pelo fungo Curvularia eragrostidis (Henn.) Meyer [teleomorfo Cochliobolus eragrostidis Tsuda \& U eyama], éa principal doença foliar do inhame(Dioscorea cayennensis Lam.) no N ordeste brasileiro. Os sintomas caracterizam-se por manchas foliares necróticas de coloração marrom-escura, freqüentemente circundadas por um halo amarelo, que provocam menor desenvolvimento das plantas e podem levar à completa desfolha, o que reduz drasticamente a produção de túberas $(4,8)$.

A amostragem constitui uma das mais importantes atividades no estudo de epidemias de doenças de plantas e permite a obtenção de estimativas representativas das características da epidemia a um custo reduzido, com a maior exatidão e precisão possível (2), possibilitando
0 ajuste entre o que é biológica e estatisticamente razoável (1).

A pesar da importância da queima das folhas do inhame, até o momento inexistem informações sobre procedimentos para amostragem, motivo pelo qual o presente trabal ho teve como objetivo determinar os tamanhos ideais das amostras para quantificação dessa doença, em diferentes níveis de severidade no campo.

Os experimentos foram conduzidos em 15 plantios de inhame, cultivar Da Costa, localizados na Zona da M ata do estado de Pernambuco (Tabela 1). Os plantios eram distanciados de no mínimo $4,5 \mathrm{~km}$ entre si, conduzidos no sistema de leirões e tutoramento individual das plantas, com espaçamento de 1,20 m entre linhas e 0,80 $m$ entre covas (8). Em cada plantio foi estabelecida uma subárea de 1 
Tabela 1. Número de plantas de inhame a serem amostradas para quantificação da severidade da queima das folhas (Curvularia eragrostidis), considerando três quantidades de folhas amostradas/planta.

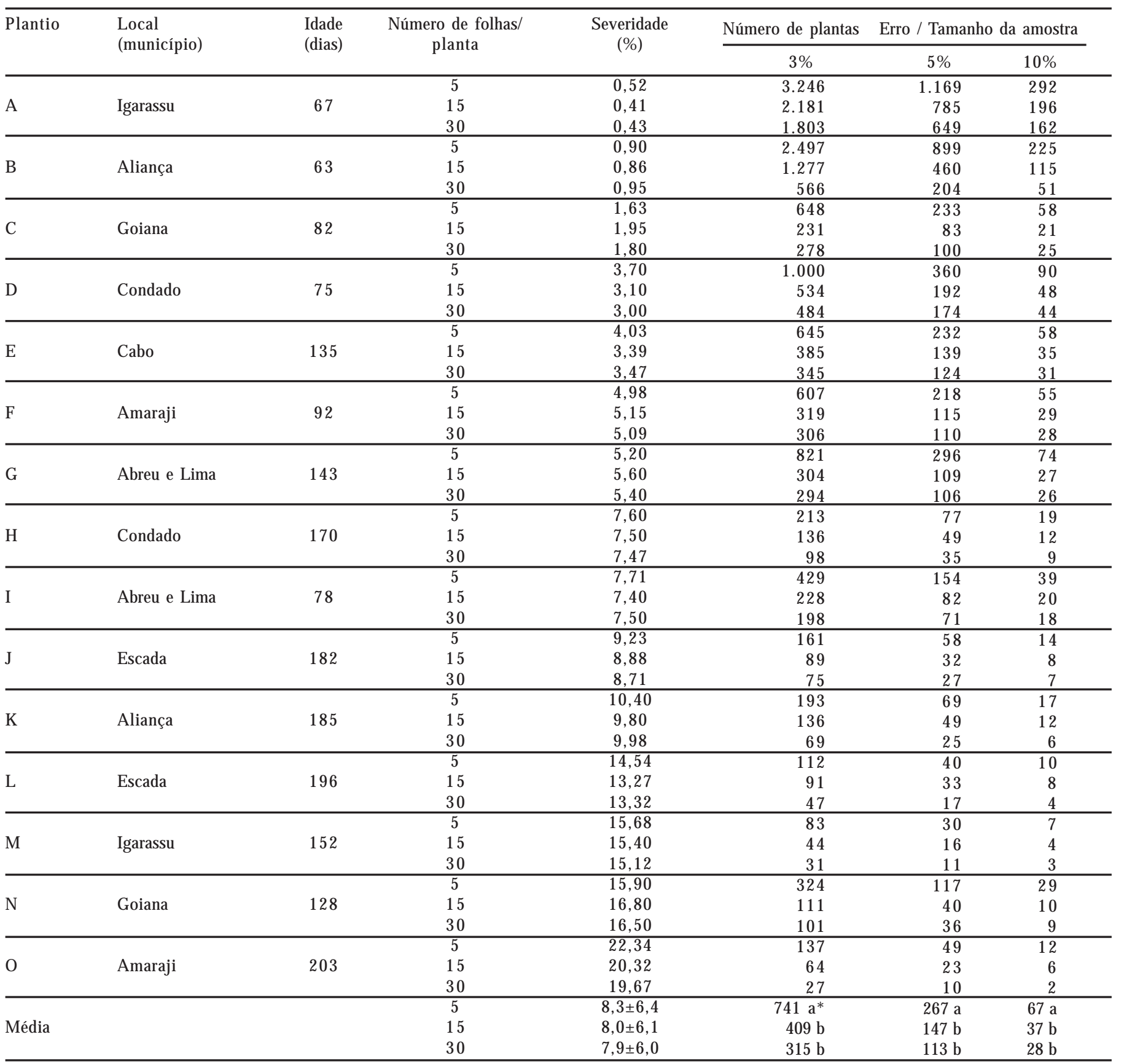

* M édias seguidas pela mesma letra na coluna não diferem significativamente entre si pelo teste de $\mathrm{K}$ ruskal-Wallis $(\mathrm{P}=0,05)$.

ha (100 x $100 \mathrm{~m}$ ), constituída de 82 linhas de plantio e 125 plantas/ linha, num total de 10.250 plantas/ha. Utilizando a técnica de amostragem sistemática, cada subárea foi percorrida no sentido Iongitudinal da linha de plantio, iniciando a amostragem na quinta linha à esquerda da subárea e saltando sete linhas para a segunda amostragem, repetindo esse procedimento até a 10 a inha a ser avaliada. Dentro de cada linha de plantio foram avaliadas 10 plantas, sendo a primeira planta amostrada a $10 \mathrm{~m}$ após o início da linha e as demais distanciadas de $10 \mathrm{~m}$. Com o auxílio de uma escala diagramática de 0 a $32 \%$ de área foliar lesionada (5), foi ef etuada a estimativa da severidade da queima das fol has nas 100 plantas selecionadas, considerando-se extratos de 5, 15 e 30 folhas/planta. No extrato de 5 folhas foram amostradas duas fol has no terço inferior, duas no terço médio e uma no terço superior da planta, enquanto nos extratos de 15 e 30 folhas foi amostrado o mesmo número de folhas nos diferentes terços da planta.

Os dados de severidade da queima das folhas do inhame obtidos nas amostragens-piloto foram analisados conforme a metodologia descrita por Campbell \& M adden (2), determinando-se os tamanhos das amostras baseado no arranjo espacial indeterminado de plantas doentes. A adoção desse procedimento se justifica pela ausência de um mesmo padrão espacial da doença em diferentes situações de campo 
(6). Os tamanhos ideais das amostras ( $n$ ) foram estabelecidos para cada área de plantio, considerando-se extratos de 5, 15 e 30 folhas avaliadas por planta, pela equação: $V=V^{2} 2 \bar{x}^{2} \mathscr{V}{ }_{x}^{2}$ ), onde $\bar{x}$ corresponde à severidade média da doença em 100 plantas com 5 , 15 ou 30 folhas/planta; à variância amostral e $V$ ao coeficiente de variação da média, considerando-seerros aceitáveis pré-estabel ecidos de 3,5 e $10 \%(=0,03 ; 0,05$ e 0,1). Utilizando os dados obtidos em cada área, foram comparados os tamanhos médios das amostras para os três extratos de folhas avaliadas por planta dentro de cada nível aceitável de erro, pelo teste de K ruskal-Wallis, ao nível de $5 \%$ de probabilidade. Para verificar a influência da idade dos plantios e dos níveis de severidade da doença nos tamanhos das amostras, foi efetuada a análise de correlação de Pearson, ao nível de 5\% de probabilidade.

A severidade da queima das fol has do inhame nos plantios variou de 0,41 a 22,34\% (Tabela 1), sendo constatadas correlações positivas $(r=0,72$ a 0,75$)$ significativas $(P=0,05)$ entre os níveis de severidade e as idades dos plantios, assemelhando-se ao verificado nesse patossistema em estudos anteriores $(4,6)$. Por outro lado, os tamanhos das amostras correlacionaram-se negativamente com os níveis de severidade da doença $(r=-0,60$ a $-0,66)$ e as idades dos plantios $(r=$ $-0,61$ a - 0,68 ) (Tabela 1 ), indicando que o número de plantas de inhame a ser amostrado reduziu com a elevação da idade do plantio e da severidade da doença.

A redução do número de amostras necessárias em função do aumento da severidade da queima das folhas do inhame indica que os valores di spersos ao redor da média também diminuíram, assemel handose ao verificado para a mancha parda da mandioca (7).

Considerando a média dos plantios, não houve diferença significativa nos tamanhos das amostras para quantificação da queima quando avaliadas 15 ou 30 folhas por planta, os quais diferiram do extrato de 5 folhas (Tabela 1). A definição do nível de erro aceitável depende do propósito da amostragem, pois em levantamentos de campo o nível de $10 \%$ é considerado adequado, enquanto em estudos com necessidade de precisão mais elevada são utilizados níveis de $5 \%$ ou $3 \%$ (9). Nesse sentido, o tamanho da amostra recomendado para quantificação da severidade da queima das fol has do inhame em levantamentos de campo é de 37 plantas/ha e 15 folhas/planta, quando considerado um erro aceitável de 10\%. A opção pela amostragem de menor número de folhas por planta, em detrimento da redução do número de plantas, justifica-se pela consideração de que a estimativa de doenças foliares é mais eficiente com o aumento do número de unidades amostradas na parcela (plantas), embora seja mais econômico 0 aumento do número de subunidades amostrais (folhas) (3).

E mbora o tamanho da amostra possa variar com o arranjo espacial da doença no campo (2), este aspecto não foi considerado no presente estudo, pois em investigação realizada previamente (6) foi constatado que os arranjos espaciais das plantas de inhame com queima das fol has variavam conforme a área de plantio e o progresso da doença.

U m pressuposto básico no uso dos diferentes métodos para estimar tamanho de amostra é de que os dados dos locais analisados sejam representativos do que poderia ocorrer em outros campos, sendo a validade desses pressupostos variável entre patossistemas (2). Portanto, os resultados obtidos nesse estudo servem como base para futuros levantamentos epidemiológicos da queima das folhas do inhame, uma vez que os dados foram originados de campos sob diferentes condições e estimados considerando necessidades crescentes de precisão.

\section{REFERÊNCIASBIBLIOGRÁFICAS}

1. Campbell, C.L.; Duthie, J.A. Special report: sampling for disease assessment. Biological and Cultural Tests for Control of Plant Diseases, St. Paul, v.4, p.5-8, 1989.

2. Campbell, C.L.; M adden, L.V. Introduction to plant disease epidemiology. New York: John Willey, 1990. 532p.

3. Duthie, J.A.; Campbell, C.L.; Nelson, L.A. Efficiency of multistage sampling for estimating of intensity of leaf spot diseases of alfalfa in field experiments. Phytopathology, St. Paul, v.81, n.9, p.959-964, 1991.

4. M ichereff, S.J.; M affia, L.A.; Noronha, M.A.; Pedrosa, R.A.; Coelho, R.S.B. Levantamento da intensidade da queima das folhas do inhame, causada por Curvularia eragrostidis, na Zona da M ata de Pernambuco. Fitopatologia Brasileira, Brasília, v.24, n.4, p.556-560, 1999.

5. M ichereff, S.J .; M affia, L.A.; N oronha, M.A. Escala diagramática para avaliação da severidade da queima das folhas do inhame. Fitopatologia Brasileira, Fortaleza, v.25, n.4, p.612-619, 2000.

6. Michereff, S.J.; M affia, L.A.; Pedrosa, R.A. Progresso e arranjo especial da queima das folhas do inhame causada por Curvularia eragrostidis, na Zona da M ata de Pernambuco. Agrotrópica, Itabuna, v.12, n.1, p.87-94, 2000.

7. Michereff, S.J.; Pedrosa, R.A.; Noronha, M.A.; M artins, R.B.; Silva, F.V. Escala diagramática e tamanho de amostras para avaliação da severidade da mancha parda da mandioca (Cercosporidium henningsii). Agrotrópica, Itabuna, v.10, n.3, p.143-148, 1998.

8. Santos, E.S. M anejo sustentável da cultura do inhame (Dioscorea sp.) no Nordeste do Brasil. In: Simpósio Nacional sobre as Culturas do Inhame e do Taro, 2., João Pessoa, PB. 2002. A nais. João Pessoa: EMEPA, 2002. v.1, p.181-195.

9. Southwood, T.R.E. Ecological methods. 2.ed. London: Chapman \& Hall, 1978. 524p. 